Special issue of the International Conference on Computational and Experimental Science and Engineering (ICCESEN 2014)

\title{
A Comparison for Grain Size Calculation of Cu-Zn Alloys with Genetic Programming and Neural Networks
}

\author{
İ. H. KARAHAN ${ }^{a, *}$ AND R. ÖZDEMIR ${ }^{b}$ \\ ${ }^{a}$ Department of Physics, Faculty of art and Science, Mustafa Kemal University, 31040 Hatay, Turkey \\ ${ }^{b}$ Kilis Vocational High School, Kilis 7 Aralık University, 79000 Kilis, Turkey
}

\begin{abstract}
Neural Networks (NN) and Genetic Programming (GP) were used as a new method for formulation of grain size of electrodeposited $\mathrm{Cu}_{1-x} \mathrm{Zn}_{x}$ alloys as a function of Zinc and Copper content both electrolyte and the alloy films produced by electrodeposition technique. To predict grain size a great number of different expression models genetic programming and neural network were conducted. Each model differs from the other with their linking function, number of genes, head size, and chromosomes. To generate databases for the new grain size formulations, testing and training sets in total of 134 samples were selected at different $\mathrm{Zn}$ and $\mathrm{Cu}$ ratios of components. 6 different input parameters were selected and the output parameter was grain size of the electrodeposited $\mathrm{Cu}-\mathrm{Zn}$ alloys. The testing and training sets consisted of randomly selected 106 and 28 for the proposed models. All results in the models indicated an applicable performance for predicting grain size of the alloys and found reliable. The predicted model showed that all of the input parameters effected on the resulting grain size. The NN and GEP based formulation results are compared with experimental results and found to be quite reliable with a very high correlation $(\mathrm{R} 2=0.995$ for GEP and 0.999 for $\mathrm{NN})$.
\end{abstract}

DOI: 10.12693/APhysPolA.128.B-427

PACS: 07.05.Mh, 81.15.Pq

\section{Introduction}

The shape memory alloys (SMA) are special materials in which physical properties can be modified by temperature variation. These materials may be used as a sensor and/or actuator and have potential use in various areas, such as biomedical, aerospace, automotive, eyewear, and microsystems. SMAs have also been implemented in various composites for use in new potential applications due to their high ductility and strength, good corrosion resistance and high damping capability. $\mathrm{Cu}-\mathrm{Zn}$ alloy has been the most widely used for the joint of the device material and the water pipe of constructional plant, pseudoelasticity which is ally with the specific way the phase transformation occurs. $\mathrm{Cu}-\mathrm{Zn}$ alloys have been extensively used in scientific applications and industry, owing to their attractive properties such as adhesion to steel, protection against corrosion, pipe and aircraft hydraulic couplings, various actuators in electric appliances, electrical connectors, microelectromechanical systems, automobile applications, antennae for cellular phones valves in fire-safety devices, robotic muscles, and surgical tools and biomedical implant materials, and decorative property besides the SMA properties [1-6].

The properties of the alloys are strictly related with preparation techniques [7-10]. There are many different synthesis methods such as physical vapour deposition, chemical vapour deposition, molecular beam epitaxy, spin coating and electrodeposition. Electrodeposition is an alternative production method for the deposition of

*corresponding author; e-mail: ikarahan@mku.edu.tr metallic alloys. The electrodeposited thin film depends on various parameters like temperature, $\mathrm{pH}$, voltage, current density, and concentration of electrolyte has many numerous effects on the brightness, hardness, porosity and grain size of the deposited thin film. Dudin et al. [11] illustrated that the grain size of nickel coatings decreased from $70 \mathrm{~nm}$ to $40 \mathrm{~nm}$ by increasing the current density from 1 to $30 \mathrm{mAdm}^{-2}$. Garcia et al. showed that the changing chemical composition of the coatings was changed the grain sizes of the $\mathrm{Cu}-\mathrm{Zn}$ alloys [12]. PinQiang et al. [13] found that the grain size of nickel deposits decreased from $50 \mathrm{~nm}$ to about $20 \mathrm{~nm}$ by increasing the current density from 50 to $100 \mathrm{~mA} / \mathrm{cm}^{2}$.

Artificial neural networks, systems, fuzzy logic, adaptive neuro-fuzzy interfacial and GP are common Soft computing techniques are preferred if the numbers of the accessible data are appropriate. In our previous work [14], GP was used for the formulations of mAgnetoresistance and electrical resistivity properties of electrodeposited $\mathrm{Cu}-\mathrm{Co}-\mathrm{Ni}$ alloys. In another study, empirical formulations were proposed by applying the GP for prediction of electrical resistivity of Zn-Fe alloys. In our another study empirical formulations were proposed by applying the GP for prediction of grain size $G$ of $\mathrm{Cu}-\mathrm{Zn}$ alloys. There are a lot of papers about the applications of GEP in the literature for different engineering problems. Cevik and Guzelbey [15] used the GEP and predicted the ultimate strength of metal plates in compression. Eskil and Kanca [16] tried to develop a GP based formulation about the effect of changing composition and heat treatments on the mArtensite start temperature of FeMnSi shape memory alloys. Nazari and Abdinejad predicted a new formulation for Charpy impact energy of laminated $\mathrm{Al} / \mathrm{SiCP}$ nanocomposites [17]. Rashidi et al. 
a feed-forwarded multilayer perceptron artificial neural network framework were used to model the dependence of the grain size of nano-crystalline nickel coatings on the process parameters namely current density, saccharin concentration and bath temperature. In our latest study, empirical formulations were proposed by applying the NN and GEP for prediction of $G$ of $\mathrm{Cu}-\mathrm{Zn}$ alloys. These formulations were compared with each other [18].

TABLE I

The electrolyte composition and experimental parameters for the $\mathrm{Cu}-\mathrm{Zn}$ films.

\begin{tabular}{|c|c|c|c|c|c|c|c|c|c|}
\hline \multirow{3}{*}{$\begin{array}{l}\text { Film } \\
\text { No. }\end{array}$} & \multirow{3}{*}{$\begin{array}{l}\text { thin } \\
\text { films }\end{array}$} & \multicolumn{3}{|c|}{ electrolyte in materials } & \multirow{3}{*}{$\mathrm{pH}$} & \multirow{3}{*}{$\begin{array}{c}\text { current } \\
{[\mathrm{mA}]}\end{array}$} & \multirow{3}{*}{$\begin{array}{l}\text { time } \\
{[\min .]}\end{array}$} & \multirow{3}{*}{$\begin{array}{c}\text { temperature } \\
{\left[{ }^{\circ} \mathrm{C}\right]}\end{array}$} & \multirow{3}{*}{$\begin{array}{c}\text { aluminum } \\
\text { substrate area } \\
{\left[\mathrm{cm}^{2}\right]}\end{array}$} \\
\hline & & $\mathrm{CuSO}_{4} \cdot 5 \mathrm{H}_{2} \mathrm{O}$ & $\mathrm{ZnSO}_{4} \cdot 7 \mathrm{H}_{2} \mathrm{O}$ & $\mathrm{Na}_{3} \mathrm{C}_{6} \mathrm{H}_{5} \mathrm{O}_{7}$ & & & & & \\
\hline & & \multicolumn{3}{|c|}{$[\mathrm{mol} / \mathrm{lt}]$} & & & & & \\
\hline 1 & $\mathrm{Cu}_{26} \mathrm{Zn}_{74}$ & 0.06 & 0.2 & 0.5 & 5.8 & 60 & 60 & 20 & 3.8 \\
\hline 2 & $\mathrm{Cu}_{37} \mathrm{Zn}_{63}$ & 0.08 & 0.2 & 0.5 & 5.8 & 60 & 60 & 20 & 3.8 \\
\hline 3 & $\mathrm{Cu}_{52} \mathrm{Zn}_{48}$ & 0.1 & 0.2 & 0.5 & 5.8 & 60 & 60 & 20 & 3.8 \\
\hline 4 & $\mathrm{Cu}_{62} \mathrm{Zn}_{38}$ & 0.06 & 0.1 & 0.5 & 5.8 & 60 & 60 & 20 & 3.8 \\
\hline 5 & $\mathrm{Cu}_{25} \mathrm{Zn}_{75}$ & 0.06 & 0.3 & 0.5 & 5.8 & 60 & 60 & 20 & 3.8 \\
\hline 6 & $\mathrm{Cu}_{21} \mathrm{Zn}_{79}$ & 0.06 & 0.4 & 0.5 & 5.8 & 60 & 60 & 20 & 3.8 \\
\hline 7 & $\mathrm{Cu}_{38} \mathrm{Zn}_{62}$ & 0.06 & 0.2 & 0.3 & 5.8 & 60 & 60 & 20 & 3.8 \\
\hline 8 & $\mathrm{Cu}_{26} \mathrm{Zn}_{74}$ & 0.06 & 0.2 & 0.5 & 5.8 & 60 & 60 & 20 & 3.8 \\
\hline 9 & $\mathrm{Cu}_{6} \mathrm{Zn}_{94}$ & 0.06 & 0.2 & 0.7 & 5.8 & 60 & 60 & 20 & 3.8 \\
\hline 10 & $\mathrm{Cu}_{13} \mathrm{Zn}_{87}$ & 0.06 & 0.2 & 0.9 & 5.8 & 60 & 60 & 20 & 3.8 \\
\hline 11 & $\mathrm{Cu}_{86} \mathrm{Zn}_{14}$ & 0.08 & 0.2 & 0.5 & 5.8 & 10 & 40 & 20 & 3.8 \\
\hline 12 & $\mathrm{Cu}_{66} \mathrm{Zn}_{34}$ & 0.08 & 0.2 & 0.5 & 5.8 & 20 & 40 & 20 & 3.8 \\
\hline 13 & $\mathrm{Cu}_{48} \mathrm{Zn}_{52}$ & 0.08 & 0.2 & 0.5 & 5.8 & 30 & 40 & 20 & 3.8 \\
\hline 14 & $\mathrm{Cu}_{47} \mathrm{Zn}_{53}$ & 0.08 & 0.2 & 0.5 & 5.8 & 40 & 40 & 20 & 3.8 \\
\hline 15 & $\mathrm{Cu}_{43} \mathrm{Zn}_{57}$ & 0.08 & 0.2 & 0.5 & 5.8 & 60 & 40 & 20 & 3.8 \\
\hline 16 & $\mathrm{Cu}_{17} \mathrm{Zn}_{83}$ & 0.08 & 0.2 & 0.5 & 5.8 & 80 & 40 & 20 & 3.8 \\
\hline 17 & $\mathrm{Cu}_{25} \mathrm{Zn}_{75}$ & 0.08 & 0.2 & 0.5 & 5.8 & 100 & 40 & 20 & 3.8 \\
\hline 18 & $\mathrm{Cu}_{13} \mathrm{Zn}_{87}$ & 0.06 & 0.2 & 0.5 & 5.8 & 60 & 20 & 20 & 3.8 \\
\hline 19 & $\mathrm{Cu}_{12} \mathrm{Zn}_{88}$ & 0.06 & 0.2 & 0.5 & 5.8 & 60 & 30 & 20 & 3.8 \\
\hline 20 & $\mathrm{Cu}_{5} \mathrm{Zn}_{95}$ & 0.06 & 0.2 & 0.5 & 5.8 & 60 & 40 & 20 & 3.8 \\
\hline 21 & $\mathrm{Cu}_{17} \mathrm{Zn}_{83}$ & 0.06 & 0.2 & 0.5 & 5.8 & 60 & 50 & 20 & 3.8 \\
\hline 22 & $\mathrm{Cu}_{7} \mathrm{Zn}_{93}$ & 0.06 & 0.2 & 0.5 & 5.8 & 60 & 60 & 20 & 3.8 \\
\hline
\end{tabular}

Artificial neural networks (ANNs) that possess massive parallel computing capability and can map the input-output relationships have attracted significant attention in research on mAterial processing and properties. The crystallographic texture, grain morphology, and grain size properties of thin films affected from the grain structure of the materials. Grain morphology and size is related to physical properties of thin film and the behavior of metals influenced with the grain size. Grain sizes in the electrodeposited materials are usually determined via direct observations under high magnified electron microscopy, or by estimations from the X-ray diffraction data. Generally, in the literature the grain size $D$ was estimated using the Scherrer formula Eq. (1) [19]

$$
D=\frac{0.9 \lambda}{\beta \cos \theta}
$$

where $\beta$ the full width at half maximum of the peak in radians and $\theta$ the Bragg angle of the X-ray diffraction peak, and $\lambda$ is the wavelength of X-Ray used (1.5400 $\AA$ ).
The above mentioned mathematical model was derived from physical descriptions. This model usually is computationally unclear, mathematically complex, and requires detailed knowledge of the XRD process. Therefore, alternative methods for designation of the Scherrer formula by using available process data and enlarging it to a usable mathematical model, which can be applied simply on unavailable data, are so worthwhile. To the best of our knowledge, there is no work in the field of modelling of grain size estimation by means of GP and NN for the $\mathrm{Cu}-\mathrm{Zn}$ alloys.

The literature is lack of a clear formulation for estimating the grain size of electrodeposited alloys related to bath and film component. For this purpose, in this work, NN and GEP were preferred to predict and present suitable formulation of grain size of electrodeposited $\mathrm{Cu}-$ $\mathrm{Zn}$ alloys. It would be useful to have a quantitative relationship between bath and film composition, FWHM, and grain size of $\mathrm{Cu}-\mathrm{Zn}$ alloys. Hundred and thirty four 
input-target data were gathered from the previous work done in our laboratory, randomly selected and divided into 106 and 28 data sets and then were respectively trained and tested by the proposed models. 6 different input parameters were selected as $d$-spacing, $\mathrm{Zn}$ and $\mathrm{Cu}$ content in the electrolyte $\left(E_{\mathrm{Zn}} \& E_{\mathrm{Cu}}\right)$ and thin films $\left(F_{\mathrm{Zn}} \& F_{\mathrm{Cu}}\right)$ and the test FWHM $\left(F_{W}\right)$ of the thin films obtained by XRD results. The output parameter was grain size $G$ of the electrodeposited $\mathrm{Cu}$-Zn alloys.

\section{Experimental}

Electrodeposition was realized in a conventional glassy cell. The electrolyte composition and experimental parameters for the $\mathrm{Cu}-\mathrm{Zn}$ films are reported in Table I. The solutions were prepared using double distilled water and the chemicals are of high purity.

Table I gives the experimental conditions.

The main focus of this study is to compare the formulations for grainsize of electrodeposited $\mathrm{Cu}-\mathrm{Zn}$ alloys using GEP and NN which were based on experimental results gathered from the literature. In order to achieve explicit formulations for $G$, experimentally founded weight percentages of zinc and copper in the film and in the electrolyte, measurement $d$-spacing, and calculated FWHM of the films were employed as the input parameters of the proposed NN and GP model. The details of the experimental database including the different input parameters and ranges are presented in Table II and III, 134 experimental results of $\mathrm{Cu}-\mathrm{Zn}$ alloys were collected for building the NN and GEP models.

TABLE II

The variables used in model construction with GEP.

\begin{tabular}{c|c|c}
\hline \hline code & variable & range \\
\hline \multicolumn{3}{|c}{ input } \\
\hline$d_{0}$ & $d$ & $1.2031-2.7251$ \\
$d_{1}$ & $F_{W}$ & $0.11-1.148$ \\
$d_{2}$ & $E_{\mathrm{Cu}}$ & $13.04-37.5 \mathrm{wt} . \%$ \\
$d_{3}$ & $E_{\mathrm{Zn}}$ & $62.50-86.96 \mathrm{wt} . \%$ \\
$d_{4}$ & $F_{\mathrm{Cu}}$ & $4.76-85.56 \mathrm{wt} . \%$ \\
$d_{5}$ & $F_{\mathrm{Zn}}$ & $14.45-95.24 \mathrm{wt} . \%$ \\
\hline \multicolumn{2}{|c}{ output } \\
\hline D.V & $G$ & $33.125-771.125 \mathrm{~nm}$
\end{tabular}

\section{Results and discussion}

Regarding $G$ formulations, a set of one hundred six data were used to train the model while twenty-eight data were involved in testing. The data were randomly selected to generate both the training and testing sets. Figure 1 shows the training and test evaluation of the GEP and NN methods in a comparative way for $G$ prediction and they also demonstrated that the GEP and NN was quite successful in learning the relationship between the different input parameters and the outputs $(G)$. We understand from the results that the NN was more capable of generalizing the relationship between input variables and the output reasonably well than the GEP results.
TABLE III

Ranges and normalization coefficients of input and output parameters for NN.

\begin{tabular}{l|c|c|c|c}
\hline \hline parameter & min. & max. & \multicolumn{2}{c}{ norm. coeff. } \\
\cline { 3 - 5 } & & & $c$ & $d$ \\
\hline \multicolumn{5}{c}{ independent variables } \\
\hline$d[\AA]$ & 1.2031 & 2.7251 & 1.1826 & -2.3228 \\
$F_{W}$ & 0.11 & 1.148 & 1.7341 & -1.0907 \\
$E_{\text {Cu wt. } \%}$ & 13.04 & 37.50 & 0.0735 & -1.8596 \\
$E_{\text {Zn wt. } \%}$ & 62.5 & 86.96 & 0.0735 & -5.4993 \\
$F_{\text {Cu wt. } \%}$ & 4.96 & 85.56 & 0.0222 & -1.0060 \\
$F_{\text {Zn wt. } \%}$ & 14.45 & 95.24 & 0.0222 & -1.2219 \\
\hline \multicolumn{5}{c}{ dependent variable } \\
\hline$G[\mathrm{~nm}]$ & 33.125 & 771.124 & \\
\hline
\end{tabular}
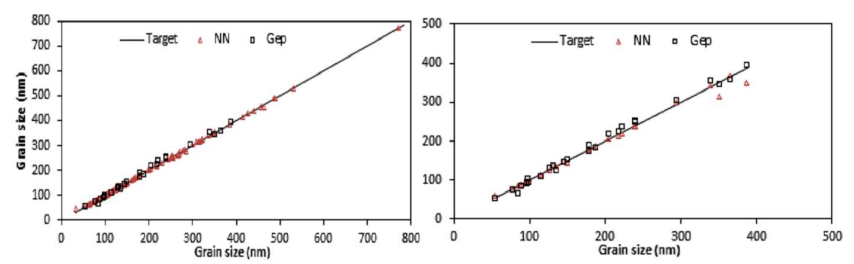

Fig. 1. Training and test evaluation of the NN and GEP methods for $G$ prediction, respectively.

Although a high prediction capability was achieved for both data sets (training and testing) from the performance of the proposed explicit formulations, the NN appears to have a high generalization capability according to GEP. The overall performances of both sets for formulations were appraised via mean square error (MSE), percentage error, and the correlations coefficient $(\mathrm{R})$. As seen in Table IV that a high coefficient of correlation and a low mean square error were obtained for the training and testing data sets for NN formulation. The proposed NN model for $G$ had correlation coefficients of 0.9997 and 0.9956 for training data set and testing data set, respectively. Moreover, the mean square error of $G$ formulation was about 0.000048 and 0.0006 for the training and testing set, respectively. These mean square errors are quite reasonable. Furthermore, the models provided highly reasonable percentage errors of as low as $1.48 \%$ for the training and $2.22 \%$ testing sets of $G$ of CuZn alloys.

A 6-4-1 NN architecture as shown in Fig. 2 was adopted to develop the NN model. This architecture indicates that there are six nodes in the input layer, corresponding

TABLE IV

Statistical performance of the proposed NN model for $G$.

\begin{tabular}{l|c|c}
\hline \hline statistical parameter & train set & test set \\
\hline mean sq. error (MSE) & 0.000048 & 0.0006 \\
mean abs. perc. error (MAPE) [\%] & 1.4859 & 2.2208 \\
correlation coefficient $R^{2}$ & 0.9997 & 0.9956
\end{tabular}


to six factors from measurement $d$-spacing $d$, and calculated FWHM $\left(F_{W}\right)$, four nodes in the hidden layer, and one in the output layer corresponding to $G$ of $\mathrm{Cu}-\mathrm{Zn}$ alloys.

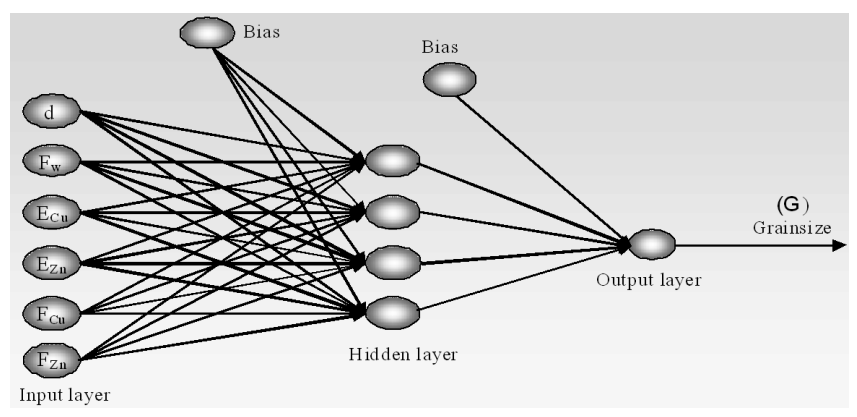

Fig. 2. Proposed NN architecture for prediction of $G$ of $\mathrm{Cu}-\mathrm{Zn}$ alloys.
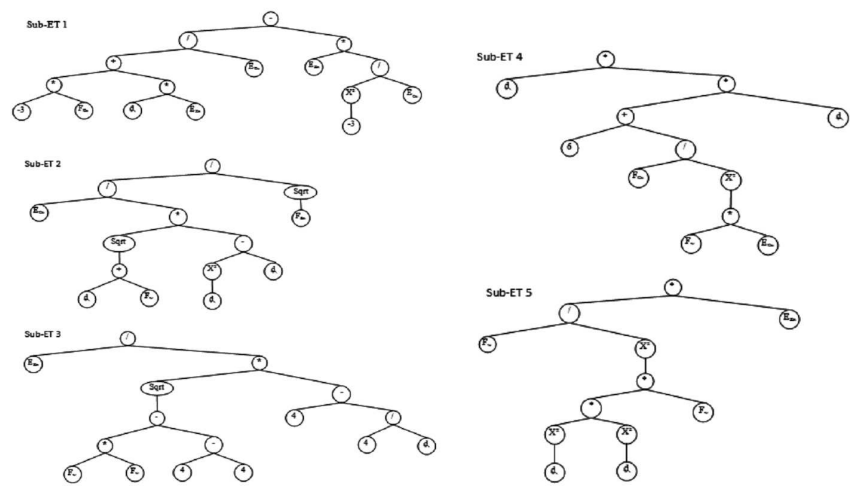

Fig. 3. Expression tree for grain size of CuZn alloys.

Running the GEP algorithm for all of these combinations requires a huge amount of computational time. Therefore, a subset of these combinations is selected intuitively to investigate the performance of the GEP algorithm in predicting $G$. Figure 3 shows the training and test evaluation of the GEP method for $G$ prediction. The optimal setting was used for the prediction of $G$ with the equations below:

$$
\begin{aligned}
& M_{1}=\frac{-3 F_{\mathrm{Cu}}+d E_{\mathrm{Zn}}}{E_{\mathrm{Cu}}}-\frac{9 E_{\mathrm{Zn}}}{E_{\mathrm{Cu}}}, \\
& M_{2}=\frac{E_{\mathrm{Cu}}}{\sqrt{d+F}\left(d^{2}-d\right) \sqrt{F_{\mathrm{Zn}}}}, \\
& M_{3}=\frac{E_{\mathrm{Zn}}}{F\left(4-\frac{4}{d}\right)}, \\
& M_{4}=d^{2}\left(6+\frac{F_{\mathrm{Cu}}}{\left(F E_{\mathrm{Cu}}\right)^{2}}\right), \\
& M_{5}=\frac{E_{\mathrm{Zn}}}{d^{8} F}, \\
& G=M_{1}+M_{2}+M_{3}+M_{4}+M_{5} .
\end{aligned}
$$

Most of the properties of the materials as mechanical properties improve as the grain size decreases. Therefore, alloy composition and processing must be carefully controlled to obtain the desired grain size. The technical application of thin metal alloy films in optical filters, catalysis or corrosion-resistant coatings, microelectronics as chips, sensor design, solar cells have led to a large dense study on the grain size properties. Grain size determines the metals density, tensile strength, and flexibility to a certain extent. The smaller the grains in the metal the higher density the metal is. Higher density means a lower flexibility and sometime tensile strength. Grain size influences from electrolyte composition thereby film composition, microstructure, ambient temperature, corrosion properties, etc.

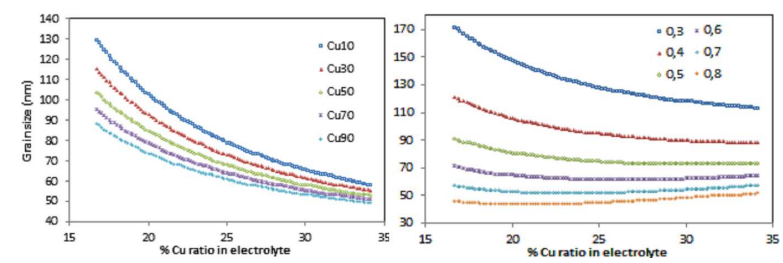

Fig. 4. Grain size changing by $\mathrm{Cu}$ ratio in the electrolyte for the NN and GEP respectively.

\section{Conclusion}

In this paper, an application of two computing techniques, namely, GEP and NN to $G$ prediction of electrodeposited $\mathrm{Cu}-\mathrm{Zn}$ alloys for various film compositions, electrolyte concentrations, FWHM, $d$-spacing are presented along with its performance comparisons. A reliable database of our previously published experimental results was used for training and testing the prediction models. The values of performance measures for the models indicate that the proposed formulations are able to predict the target values to high degree of accuracy. It should also be remarked that the results of the proposed NN formulations are also compared with results of GEP formulations and are found to be more accurate for all cases. GEP and NN may serve as a robust approach and they may open a new era for the accurate and effective explicit formulation of many condensed matter problems. Common results obtained are as follows,

1. GEP and NN have an important advantage coming from their ability to generate mathematical equations that can be easily programmed even into calculators for use in everyday practices during the production process. This investigation revealed that GEP and NN are very promising approach for its future applications to the formulation of many physics tasks.

2. The results showed that the GEP and NN were quite successful in learning the relationship between the different input parameters and the output. Performance of the result formulations showed 
that the NN was more capable of generalizing between input variables and the output reasonably well than the GEP results. The NN appears to have a high generalization capability.

3. NN results show that increasing $\mathrm{Cu}$ content in the film between $10 \%$ and $90 \%$ change $G$ gradually but more addition of $\mathrm{Cu}$ decreases $G$ at $\mathrm{CuZn}$ alloys slightly.

4. The increase in FWHM is decrease $G$ of the films.

5. The theoretical analysis of CuZn alloy system is quite complicated due to various factors. Based on all these result, the bath composition, film composition, FWHM and $d$-spacing strongly influences $G$ of electrodeposited $\mathrm{CuZn}$ alloys.

\section{References}

[1] A.H. Alavi, A.H. Gandomi, Eng. Computation 28, 242 (2011).

[2] A.H. Alavi, A.H. Gandomi, Comput. Struct. 89, 2176 (2011).

[3] A.F. Asbour, L.F. Alvarez, V.V. Toropov, Comput. Struct. 81, 331 (2003).

[4] A. Brenner, Electrodeposition of Alloys - Principles and Practice, Academic Press, New York 1963.

[5] E.Budman, R. Sizelove, www.metalfinishing.com.
[6] A. Cevik, J. Contruct. Steel Res. 63, 1305 (2007).

[7] A. Cevik, A.F. Cabalar, Expert Syst. Appl. 36, 7749 (2009).

[8] C.T. Cheng, W.C. Wang, D.M. Xu, K.W. Chau, Water Resour. Manag. 22, 895 (2008).

[9] J.V. Davidson, D.A. Savic, G.A. Walters, Inform. Sciences 150, 95 (2003).

[10] C. Ferreira, in: Invited Tutorial of the 6th Online World Conference on Soft Computing in Industrial Applications, 2001, p. 10.

[11] P.V. Dudin, O.V. Reva, T.N. Vorobyova, Surf. Coat. Tech. 204, 3141 (2010).

[12] J.R. Garciaa, D.C. Baptista do Lagoa, F.L.G. Silvaa, E. D'Eliab, A.S. Lunaa, L. Ferreira de Sennaa, Mat. Res. 16, 392 (2013).

[13] D. Pin-Qiang, Y. Hui, L. Qiang, Trans. Mater. Heat Treatment 25, 1283 (2004).

[14] I.H. Karahan, O.F. Bakkaloglu, H.S. Guder, J. Optoelectron. Adv. M. 11, 313 (2009).

[15] A. Cevik, I.H. Guzelbey, Eng. Struct. 29, 383 (2007).

[16] M. Eskil, E. Kanca, Comp. Mater. Sci. 43, 774 (2008).

[17] A. Nazari, V. Abdinejad, Ceram. Int. 391991 (2013).

[18] İ.H. Karahan, R. Ozdemir, B. Erkayman, Appl. Phys. 2013, 1 (2013).

[19] B.D. Cullity, S.R. Stock, Elements of X-Ray Diffraction, 3rd ed., Prentice Hall, New Jersey 2001, p. 170. 